\title{
Values, strengths and futures of museums, libraries and community centres as seen by experts in the field: First round results of a Delphi study ${ }^{1}$
}

\author{
János Tóth
}

János Tóth, PhD.

Kodolanyi Janos University

Institute of Cultural, Communication and Media Studies

Department of Communication and Media Studies

st. Frangepán 50-56

Budapest 1139

Hungary

e-mail: tothjanj@gmail.com

Muzeológia a kulturne dedičstvo, 2020, 8:2:55-75

DOI: $10.46284 / \mathrm{mkd} .2020 .8 .2 .4$

Values, strengths and futures of museums, libraries and community centres as seen by experts in the field: First round results of a Delphi study

In the process of building local communities with shared cultural values, museums, libraries and community centres are key agents in civil society. When these institutions project specific notions and ideal types of identity and citizenship, they have the potential to produce changes in people's behaviour. It is only natural that political bodies are interested in these processes. On 16 September 2016, the Ministry of Human Capacities of the Hungarian Government launched an EU-funded project with the primary aim of strengthening social cohesion within the region. As a part of this project, we surveyed 59 professionals working in Hungarian museums, libraries and community centres, using the Delphi method, to gain insights about their capacities, needs, and visions. This article presents the results of the first round of analysis. Respondents' answers were analysed using NVivo qualitative data analysis software, which resulted in a thematic map showing the main problems professionals in these sectors are struggling with, and highlighting the kinds of visions they had for their institutions' future. The study clearly shows that the cultural sector is plagued by financial problems, and that there is a strong need for reform when it comes to the professional training of workers in these fields. Regarding the future, visions are centred around cultural institutions increasingly becoming community spaces, thinktanks, and ideas workshops that consciously guide community formation.

Keywords: museums, libraries, Delphi method, experts, group judgement, forecasting

\section{Introduction}

On 16 September 2016, the Ministry of Human Capacities of the Hungarian Government launched a project with the primary aim of strengthening social cohesion within the region. Funded by the European Union, a project entitled "Acting Communities - Active Community Involvement" offered the means to realize this aim by increasing the involvement of community

\footnotetext{
${ }^{1}$ Acknowledgement: I would like to express my gratitude to Renáta Csorba and Ágnes Schattmann for their contribution to data collection and to Gabriella Szilvia Kuhn for her contribution to the analysis. This article is based on the research reports of the EU-funded project „Cselekvő közösségek - aktív közösségi szerepvállalás” (EFOP-1.3.1-15-2016-00001) available at https://cselekvokozossegek.hu/wp-content/uploads/Delfi-j\%C3\%B6v\%C5\%91-\%C3\%A9s-trendkutat $\% \mathrm{C} 3 \% \mathrm{~A} 1$ s_angol-nyelven.pdf and https://cselekvokozossegek.hu/wp-content/uploads/Delfi-j\%C3\%B6v\%C5\%91-\%C3\%A9s-trendkutat $\%$ C3\%A1s-web.pdf
} 
János Tóth: Values, strengths and futures of museums, libraries and community centres as seen by experts...

centres $^{2}$, libraries and museums ${ }^{3}$. This increased involvement of cultural institutions comes at a time when parts of the public sector are under pressure from economic and political restructuring, as well as ongoing changes associated with party-political skirmishes over cultural influences, the debate around which is also divided along disciplinary and nationalistic lines. The Ministry of Human Capacities is confronted with the question of how and on what basis to allocate scarce and limited resources among competing projects. In addition, it must also seek to target its support-which can be actuated in a variety of ways-where it is needed the most, ensuring the available resources to address problems relating to social cohesion are deployed where they can have the greatest impact.

In this context, it is extremely important that support for new initiatives, newly introduced community development techniques, and specific improvements in local social communities effectuated by local governments and other organizations rely on data-based decisions. It is equally important that this data should reflect the visions, needs and capacities of the actual people in question: more specifically, of those elected or appointed experts who form, implement, and supervise the policies affecting local communities. This kind of informed approach makes it possible to identify future trends within each sector, and brings clarity to the process of assessing the situation before deciding whether to support or hinder the long-term adoption of new initiatives.

The problem is that currently, there is no previously documented knowledge, and no consensus on key topic areas among Hungarian community centre, library and museum experts that can provide insights for higher-level decision-making when it comes to developing healthy, field-specific cultural communities. To fill this gap in reliable information, we will present results from the first round of a three-round Delphi study, which consists of the aggregation, analysis, interpretation and discussion of primary data collected from 59 expert participants affiliated with Hungarian institutions.

\section{The future of museums, libraries and community centres: theoretical framework,} key concepts and literature review

The theoretical frameworks of this study are embedded in a social constructivist approach. The social construction of visual meaning can be looked at as a political process in which meaning and power are inextricably linked ${ }^{4}$. Interactions with interpretations based on the material and intellectual cultural memories of previous generations are assumed to shape the way of thinking and behaviour of those who communicate with the past through them. Sharing the same cultural codes paves the way to a more-or-less shared common identity among people

\footnotetext{
${ }^{2}$ By community centres, we refer to local public institutions based in villages, towns and cities offering education and cultural activities to the people of that neighbourhood. As well as providing a venue for local theatrical or musical events, some posess small collections of assorted books and magazines, and may host exhibitions of work by local artists; however, they are less specialised in these activities than libraries and museums.

3 ARAPOVICS, Maria, PONYI, Laszlo and BODOG, Andras (eds.) The Examination of Cultural Community Development Processes in the Municipalities of Hungary. Budapest: Hungarian Open Air Museum-Museum Education and Methodology Centre, NMI Institute for Culture Non-profit Ltd and National Széchényi Library, 2019.

${ }^{4}$ STOCCHETTI, Matteo. Digital Visuality and Social Representation. Research Notes on the Visual Construction of Meaning. In: KOME—An International Journal of Pure Communication Inquiry, vol. 5, 2017, No.2, pp. 38-56.
} 
distant from each other in space and/or time ${ }^{5,6}$. Memory institutions ${ }^{7}$ that mediate between the past, present and future are of central importance both to the current Hungarian government and to the European Commission, which, based on Article 3.3 of the Lisbon Treaty, not only safeguards European cultural heritage, but secures processes through which this past heritage can enrich the individual lives of European citizens and enhance Europe's social capital.

The framework also relies heavily on the assumption shared by a large proportion of studies looking at the future: namely, that representations are performative; they have a potential to produce changes in people's activity ${ }^{8}$. Benedict Anderson's notion of "imagined communities" has also had a significant impact on how we will try to explain our data. Anderson's line of thought establishes that projecting sentiments of belonging and brotherhood beyond those of direct experience is a primary component in forming imagined national communities, and goes back as far as what has been called the "circuit of culture"10. Representations by museums and libraries are one of the central practices involved in producing culture, and public education provides common cultural codes by which to interpret these representations in a roughly similar way. This is how institutions mediate cultural memories which, depending on the current needs of society and individuals, become socially constructed heritages ${ }^{11,12}$.

The framework emphasises the role of thematization and interpretation, as opposed to material objects and fixed meanings, since it is these features that make museums and libraries key agents in civil society: when these institutions project specific notions and ideal types of identity and citizenship, they make cultural participation a space for the formation of both a cosmopolitan and a national citizenry ${ }^{13}$.

The Acting Communities - Active Community Involvement project appears to reflect these changes and new relationships between the individual and society. By means of digital media, a certain "culture of participation" has emerged, along with the concept of the "smart audience". ${ }^{14}$ Museums and libraries have started to aim for a more dynamic engagement between their collections and their visitors. ${ }^{15} \mathrm{~A}$ report by Yarrow et al. highlighted that while, in the past, cultural institutions assumed the public would take the initiative to visit,

\footnotetext{
${ }^{5}$ APPADURAI, Arjun and BRECKENRIDGE, Carol A. Museums are good to think: Heritage on view in India. In: I. Karp et al. (eds.), Museums and communities: The politics of public culture. Washington: Smithsonian Institution Press, 1992, pp. 34-55.

${ }^{6}$ HARRISON, Rodney. Heritage: Critical Approaches. London: Routledge, 2013.

${ }^{7}$ DEMPSEY, Lorean. Scientific, Industrial, and Cultural Heritage: a shared approach. A research framework for digital libraries, museums and archives. In: Ariadne, Issue 22, 2000. http://www.ariadne.ac.uk/issue/22/dempsey/

${ }^{8}$ FULLER, Ted. and LOOGMA, Krista. Constructing futures: a social constructionist perspective on foresight methodology. In: Futures, 41, 2009, pp. 71-79.

${ }^{9}$ ANDERSON, Benedict. Imagined communities: reflections on the origin and spread of nationalism (revised and extended edition). London: Verso, 1991.

${ }^{10}$ HALL, Stuart. Representation: Cultural representations and signifying practices. Culture, Media \& Identities Series. Milton Keynes/London: The Open University \& Sage Publications Ltd., 1997.

${ }^{11}$ GRAHAM, Brian J. et al. A geography of heritage: power, culture and economy. London: Arnold. 2004.

${ }^{12}$ ASSMANN, Jan. Cultural Memory and Early Civilization: Writing, Remembrance, and Political Imagination. Cambridge: Cambridge University Press, 2011.

${ }^{13}$ CARTER, Jennifer and ORANGE, Jennifer. Contentious Terrain: Defining a human rights museology. In: Museum Management and Curatorship, vol. 27, 2012, No. 2, pp. 111-127; ORANGE, Jennifer. Translating Law into Practice: Museums and a Human Rights Community of Practice. In: Human Rights Quarterly, vol. 38, 2016, No. 3, pp. $706-735$. ${ }^{14}$ VEGLIS, Andreas and MANIOU, Theodora. The Mediated Data Model of Communication Flow: Big Data and Data Journalism. In: KOME_-An International Journal of Pure Communication Inquiry, vol. 6, 2018, No. 2, pp. 32-43.

${ }^{15}$ BLACK, Graham. Transforming museums in the twenty-first century. London: Routledge. 2011.
} 
János Tóth: Values, strengths and futures of museums, libraries and community centres as seen by experts...

most institutions are now looking at outreach and other ways to be more relevant to their communities and their customers' daily lives. The focus is now on the experience, both real and virtual, of the institution itself, as well as the institution's collections. $^{16}$

This has turned these institutions into complex social entities which facilitate the interactions, meaning-making and meaning-negotiations of heritages from the past by prioritizing, for example, which books to digitize, or which special collection or exhibition to display online, thus widening their reach and attracting more (and new) customers ${ }^{17}$. The approaches these social organizations take with regard to audiences, however, differ from each other in at least one significant point. While museums tend to influence pre-existing user communities (as visiting a museum is often a social act), libraries present heritages to individuals: people visiting a library choose reading materials for themselves or for their children. Digitization has also had different effects on the formation of communities in libraries and museums. While, in the past, museums had to be visited in order for the communication of memory to take place, books were typically borrowed and read at home; in practice, newspapers and magazines (which contain current stories, not past history) were the most common materials read in situ in libraries. This means that the museum-customer relationship was more deeply affected by the introduction of new technology-for instance, the possibility of a virtual tour of an exhibition-than the librarycustomer relationship was by ideas such as digitally accessible collections. Both developments made it possible for the communication of memory to occur at other locations, chosen by the customer, but this was something that a customer of a library already had (though to a lesser degree $^{18}$ and in a different form, with the borrowing of physical copies), while it was new to museum visitors.

On the other hand, cooperation is not limited to existing or potential customers. In fact, museums and libraries, being in a sense two branches of the same tree (in that they share similar missions and audiences, at least if we speak about public institutions, not private collections) are often involved in collaborative projects. The role of community centres in the bigger picture is twofold. First, they can provide a space for touring exhibitions of library and museum materials, helping to increase the dissemination and understanding of cultural heritage. Second, they can cooperate in various educational activities contributing to community renewal and active citizenship. These activities, falling under the communication of cultural heritage in a wider sense, benefit from a range of EU programmes and funding. ${ }^{19}$ The "Acting Communities - Active Community Involvement" project, as an example, brought Hungarian museums, libraries and community centres closer together by forming an alliance

\footnotetext{
${ }^{16}$ YARROW, Alexandra; CLUBB, Barbara and DRAPER, Jennifer-Lynn. Public Libraries, Archives and Museums: Trends in Collaboration and Co-operation. International Federation of Library Associations and Institutions Professional Reports 108, 2008, p. 5. Available online: https://www.ifla.org/publications/ifla-professional-reports-108

${ }^{17}$ GIBSON, Hannah., MORRIS, Ann and CLEEVE, Marigold. Links Between Libraries and Museums: Investigating Museum-Library Collaboration in England and the USA. In: Libri, vol. 57, 2007, No. 2, p. 63.

${ }_{18}$ There are materials that cannot be borrowed and can only be read, either in their original or preserved (on microfilm) form, in the actual building of the library.

${ }^{19} 2018$ was the European Year of Cultural Heritage, and in the past seven years, a total sum of $€ 3.2$ billion was invested in heritage from the European Regional Development Fund. A further $€ 1.2$ billion was allocated for rural heritage by the European Agricultural Fund for Rural Development, and the Seventh Framework Programme allocatad around $€ 100$ million for heritage research) (Supporting Cultural Heritage 2017).
} 
of museum and library professionals, along with local cultural experts, in order to establish a joint programme of culture-focused community development with the aim of increasing community involvement and social activity among local residents (including civil servants and local government employees).

Given the increasing significance of inter- and extra-institutional forms of cooperation, it is worth considering how librarians, education and museum professionals see their present and future roles. How do these experts conceptualise the role and position of their institutions? This question seems to be of interest to the wider academic public; however, as Huvila ${ }^{20,21}$ points out, empirical research on this topic, especially in the European context, has been scarce and limited to specific countries. There are currently no up-to-date studies on museums and library professionals' self-conceptualizations except, perhaps, with regard to the digitization of archives, texts and exhibitions, where there is agreement across the sector that nowadays a much more holistic approach - involving social, cultural, and behavioural approachesis needed to interact with audiences, beyond the mere focus on access or the adoption of digitization technologies ${ }^{22,23,24,25}$.

Outside this narrow but important territory, sporadic results from small-scale qualitative studies have failed to indicate any general trends or consensus among experts with regard to the sector's needs, visions or implementation strategies. Maceviciute and Wilson ${ }^{26}$ studied perceptions of present and future issues relating to Swedish libraries, and found (though the results were not especially decisive) that different types of library had different priorities. Concerns about the relation of libraries to education and society at large were more frequent at public, regional and school libraries, while academic and special libraries emphasised the impact of new technologies and changes in scholarly and business communication. Huvila ${ }^{27}$ found that archive, library, and museum professionals felt it was necessary to discuss and define the future of their institution with regard to its societal role, but when asked to specify their ideas about this future and the strategies needed to realise it, there was a lack of consensus about the essence of the future role of archives, museums and libraries, and especially about the means to maintain, increase and reassert their influence. ${ }^{28}$

Given the above, there is a clear gap in the literature regarding self-conceptualization of roles by museum and library experts. This gap strongly directed our research methodology.

\footnotetext{
${ }^{20}$ HUVILA, Isto. Archives, libraries and museums in the contemporary society: perspectives of the professionals. In: Proceedings of iConference, 2014, pp. 45-64.

${ }^{21}$ HUVILA, Isto. Change and stability in archives, libraries and museums: mapping professional experiences in Sweden. In: Information Research, vol. 21, No. 1, paper memo 5, 2016. http://InformationR.net/ir/21-1/memo/ memo5.html

${ }^{22}$ TONTA, Yasar. Libraries and museums in the flat world: are they becoming virtual destinations? In: Library Collections, Acquisitions, and Technical Services, vol. 32, 2008, No.1, pp. 1-9.

${ }^{23}$ PARRY, Ross (ed.). Museums in a Digital Age. London: Routledge, 2010.

${ }^{24}$ BEAZLEY, I. et al. Dulwich OnView: An art museum-based virtual community generated by the local community. In: A. Seal, J. et al. (eds.), EV A London 2010 Conference Proceedings, Electronic Workshops in Computing (eWiC), British Computer Society, 2010, pp. 79-86.

${ }^{25}$ GIANNINI, Tula and BOWEN, Jonathan. A New York Museums and Pratt partnership: Building Web collections and preparing museum professionals for the digital world. In: MW2015: Museums and the Web 2015, Chicago, USA, 8-11 April 2015.

${ }^{26}$ MACEVICIUTE, Elena \& WILSON, Thomas D. A Delphi investigation into the research needs in Swedish librarianship. In: Information Research, vol. 14, No. 4, paper 419, 2009.

${ }^{27}$ HUVILA, Archives, libraries and museums...

${ }^{28}$ HUVILA, Change and stability in archives..., p. 55
} 
János Tóth: Values, strengths and futures of museums, libraries and community centres as seen by experts...

When data from previous studies is non-existent or not available, the researcher cannot rely on quantitative analytics; rather, decision-making is best supported by results stemming from qualitative research. Among qualitative research methods, the Delphi method is widely considered to be particularly suitable in cases where information is limited or conflicting but the issues need to be addressed are complex ${ }^{29,30}$. Although Davenport and Harris ${ }^{31}$ suggest that extensive data, along with statistical and quantitative analysis, are the best options for supporting decision-makers in need of short-term predictions for the near future, this is not really applicable to the cultural environment of the Central and Eastern Europe region, including Hungary. Even if past data was available, data-based statistical predictions are trustworthy only if there is a relatively constant environment; when the period of data collection is known to be dissimilar to the past, the role of subjective opinions and "gut feelings" start to gain weight in the forecasting process ${ }^{32}$. One can hardly contest that East-Central European countries, most notably Poland and Hungary, are increasingly diverging from the EU mainstream, and are faced with politico-cultural upheaval. In Hungary, state-maintained institutions using EU funds for development find themselves in a delicate situation that is not comparable to the pre-2010 era, where cooperation between the Hungarian state and the EU was less burdened with national tensions and wartime narratives.

This turbulent environment is especially relevant in connection with meaning-making and the meaning-negotiation of heritage. Public cultural institutions have always been subject to external economic and political pressures. One difference between these two types of external influence is that while economic pressure is well known and widely experienced in the Western world, resulting in the rampant commercialization of public culture, political pressure-which is value-based, state-supported, and aims at social transformation-has been, if not non-existent, then at least somewhat less significant in old constitutional democracies. In Hungary, since the current ruling party, FIDESZ (Hungarian Civic Alliance) won a supermajority in parliament in 2010, it has been possible for value-based decisions in cultural politics to be legitimately (de jure) interpreted as the "will of the majority" against which existing constitutional guarantees are rendered powerless. This period can also be considered a turning point in Hungarian cultural policy, as attempts to alter the pre-existing cultural canon (that is, to renegotiate the body and meaning of cultural heritage considered to be of significant importance to the national culture) and introduce a new canon of the "national radical right" (nemzeti jobboldal) became stronger and stronger.

This can heavily influence not only the self-conceptualisation of experts working in cultural institutions and their visions about the future, but also their willingness to report their thoughts and opinions for research purposes, even if provided with complete anonymity. This is, naturally, not a specific challenge of the Central-Eastern Europe region; in the US, as early as the 1970s, it was being debated how a government's interest in knowing what people think

\footnotetext{
${ }^{29}$ O'FAIRCHEALLAIGH, Ciaran. Public participation and environmental impact assessment: purposes, implications, and lessons for public policymaking. Environmental Impact Assessment Review, No. 30, 2010, pp. 19-27.

${ }^{30}$ MCBRIDE, Marissa F. et al. Structured elicitation of expert judgments for threatened species assessment: a case study on a continental scale using email. In: Methods in Ecology and Evolution, vol. 3, 2012, No. 5, pp. $906-920$.

${ }^{31}$ DAVENPORT, Thomas H. and HARRIS, Jeanne G. Competing on Analytics: The New Science of Winning. Boston: HBS Press, 2007.

${ }^{32}$ SAUTER, Vicki L. Decision Support Systems for Business Intelligence. New Jersey: John Wiley \& Sons, 2010.
} 
about the future may come from its need to identify unacceptable contingencies that might require more control on its part. ${ }^{33}$

\section{Methodology: The public sector and the use of the Delphi method for forecasting}

A prerequisite for the chosen method of analysis was that it must be adequate for forecasting trends in community education institutions, museums, and libraries. These institutions serve multiple objectives, and from the viewpoint of the current study exhibit at least three important features:

1. They are sites of socialisation, providing both a frame and content for complex interactive processes that build specific knowledge and behavioural patterns, resulting in individuals becoming socially competent.

2. They are usually public institutions, meaning they are run for citizens, and are either part of a state entity, or the state administration exercises ultimate managerial control over them.

3. They are organisationally hierarchical, which allows accurate identification of decisionmakers and the distribution of decision rights across layers (both vertically and horizontally).

These characteristics were crucial in our selection of the Delphi method for analysis. It is used in a wide variety of studies, and is very popular in research on the public sector, where it is mainly used for the purposes of forecasting, communication, budgeting, and goal setting for public policy ${ }^{34}$. In the US, the Delphi method has also been used extensively to engage local communities in education policy making. ${ }^{35}$

\section{First round: Sample selection and gathering preliminary data}

The first step was to determine the characteristics of the cultural institution professionals to target for the study. Then a list with names, institutional affiliations and contact addresses of potential participants was complied. Next, preliminary contact was made with the target professionals, asking them to participate in the study. The selected candidates received an invitation in the form of a formal email containing a link to a questionnaire formed of openended questions (with the exception of the first one, which asked the name of the respondent's organization). The questionnaire was created using Survey Monkey (www.surveymonkey.com), an online tool for professional use. The link which was emailed to participants remained live for 43 days, from 6 November 2017 to 18 December 2017. Respondents were restricted from accessing the link more than once, and, based on the institutional affiliation given, a manual check after collecting the responses ensured that there were no duplicate answers, and that each answer sheet collected belonged to different respondents.

A total of 142 Hungarian professionals working in cultural institutions were contacted this way, and a total of 59 valid, fully answered questionnaires were received. All completed surveys were entered ad verbatim into Microsoft Word, then processed for analysis, including editing for typos. We used QSR International's Nvivo 11 for qualitative thematic analysis, focusing on emerging topics and frequencies.

\footnotetext{
33 SCHEELE, Sam. Reality construction as a product of Delphi interaction. In: Harold A. Linstone and Murray Turoff (eds.). The Delphi method: Techniques and applications. Reading, MA: Addison-Wesley, 2002, pp. 35-67.

${ }^{34}$ ADLER, Michael and ZIGLIO, Erio (eds.) Gazing into the oracle: The Delphi method and its application to social policy and public health. London: Jessica Kingsley Publishers, 1996.

${ }^{35}$ BAUMFIELD, Vivienne M. et al. The Delphi method: gathering expert opinion in religious education. In: British Journal of Religious Education, vol. 34, 2012, No. 1, pp. 5-19.
} 


\section{Coding and Categorization}

Respondents were anonymized; only the type of their institution remained identifiable. We divided the full corpus into various well-defined subsets of texts. This transformation was necessary because the full sample for analysis was not an organic text but its construction was guided by answering specific questions pre-defined by the researcher. These subsets, serving as source documents for the analysis, were constructed from the answers received from professionals, each subset containing all answers given to one question from the Questionnaire. For example, Q2 from the Questionnaire was "What is your opinion about the values and strengths of community development, cultural/community houses/centres, museums and libraries?" and contained all answers to Q2 from 59 professionals, with a unique identifier for institutional affiliation (Q2-LIB1, Q2-LIB2, Q2-MUS1 etc.).

The pre-defined questions partially determined the tree node framework in Nvivo. Main categories (the parent nodes in Nvivo) were fixed, while particular topics emerging from the answers became subcategories (child nodes in Nvivo). Chunks of textual data referring to a particular topic (from now on referred to as "mentions") were coded into the corresponding child node. If one respondent mentioned the same issue multiple times within one answer, that was counted (merged) as one mention, but if they referred repeatedly to the same issue across answers to different questions, that was counted once per question. Individuals were not asked to rank the importance of the issues they raised; thus the data output (number of mentions) is not weighted.

The distribution mentions allocated to all main categories constructed during the first round is as follows (Figure 1).

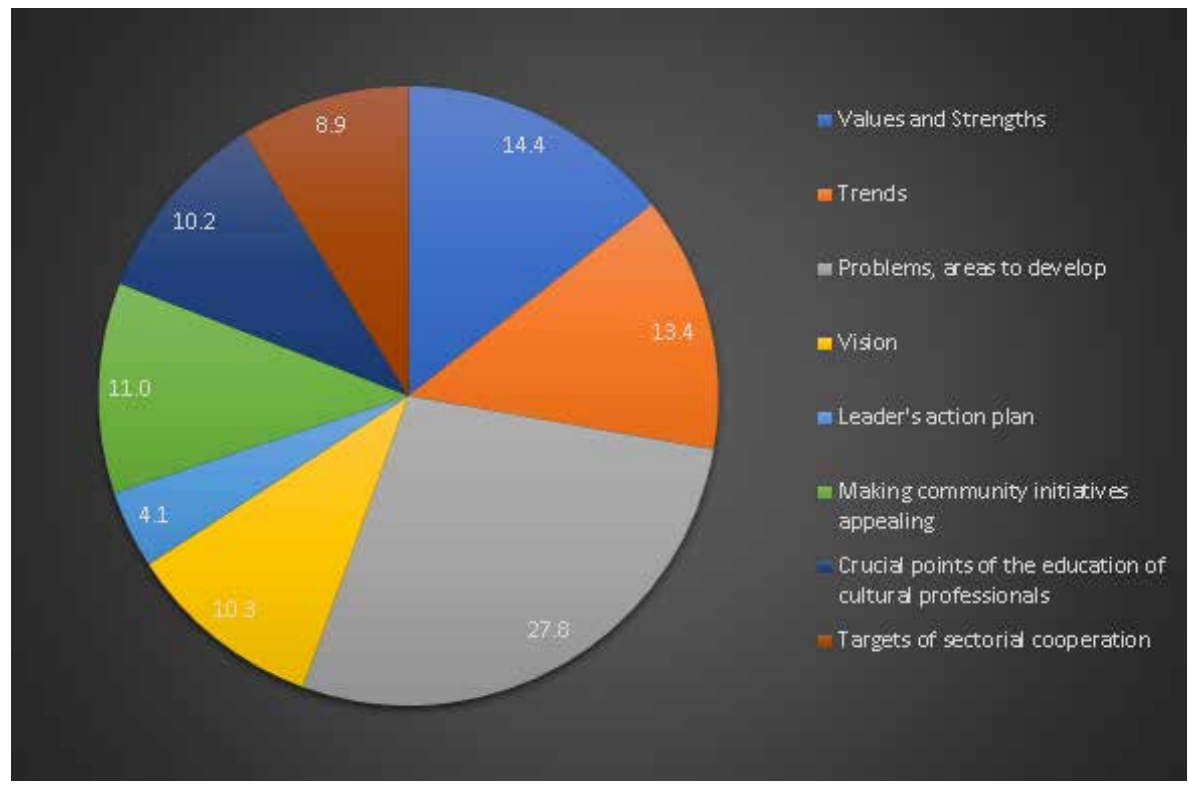

Figure 1: Distribution of main categories based on item number, in percent 
The questions and categories covered by this study were:

- Values and Strengths: Question 2

- $\quad$ Problems, areas to develop: Questions 4 and 5

- Visions - the ideal future situation in ten years' time: Question 6

\section{Results}

The sample contained similar proportions of professionals from the three types of institution covered, with 19 library professionals, 19 museum experts, and 21 from community education institutions.

\section{What are the values and strengths of libraries, museums, and community education institutions?}

From the answers received to this question, a priority list was compiled of the main functions and purposes of these institutions, as defined by the respondents. The sub-categories in this list (with a total of 248 references coded) were aggregated to create a consensus-based shared definition that applied across all three types of institution.

Aggregated results for libraries, museums and community education institutions (Figure 2) show which categories respondents considered to be most important when it came to the strengths and values these cultural institutions provide to society:

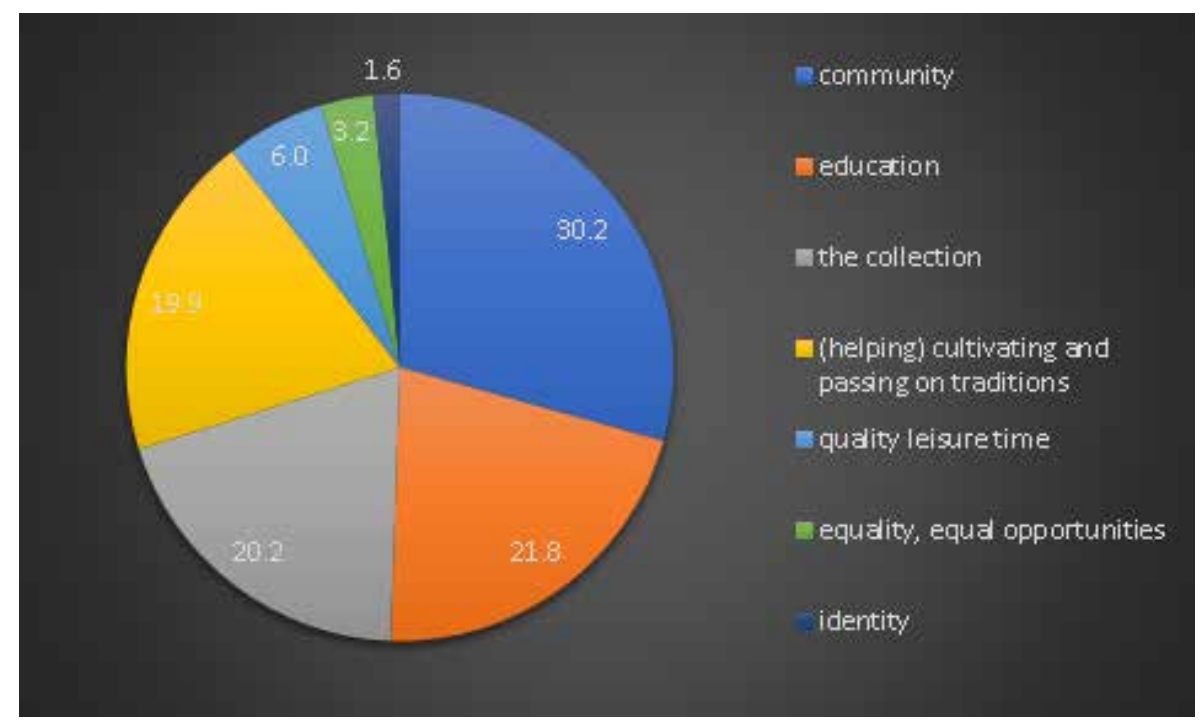

Figure 2: Relative importance of values and strengths, in percent

Respondents placed the greatest emphasis on their institution's contribution to the community, with almost one third $(30.2 \%)$ mentioning this. The second most important value, in the eyes of the surveyed professionals, was their institution's educational value, followed closely by the collection to which their institution provides access. Although providing quality leisure time $(6.0 \%)$, protecting and nurturing identities $(3.2 \%)$ and facilitating equality $(1.6 \%)$ were mentioned, they were not among the most dominant strengths and values respondents associated with their institutions.

These responses show that the most important role of these cultural institutions, according to the experts who work there, lies in their ability to establish and maintain communities. Their 
second most important role, beyond protecting and cultivating their own collections, is making them accessible to the wider public. Respondents saw these as the two key elements defining their institution's usefulness to society, which can be manifested both through education and through the passing on of traditions.

There were some differences in the weight given to institutional strengths and values depending on the type of institution. Answers given by community centre professionals diverged noticeably from responses from museum (Figure 3) and library (Figure 4) professionals, the latter pair being more similar to each other. A plausible explanation for this is that while community education centres are "active" cultural institutions, focusing more on interpersonal relations and with relatively small or non-existent collections to exhibit, museums and libraries are repositories of material objects and tend to be active agents only in the process of making these objects available for external consumption when visited by customers-if and when members of the public take the initiative to visit.

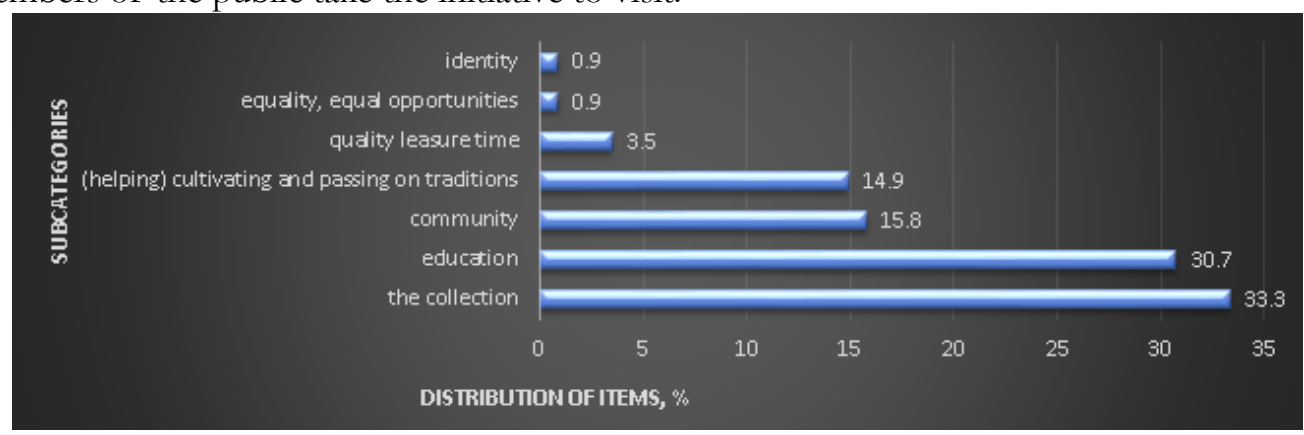

Figure 3: Relative importance of strengths and values as defined by museum professionals

A third of museum experts felt that the main values and strengths of their institution relate to its collection (33.3\%). Education $(30.7 \%)$ follows closely, mentioned approximately twice as often as either "community" (15.8\%) or "(helping) cultivating and passing on traditions" $(14.9 \%)$. Other first-level nodes with less significance were also identified: "quality leisure time", "identity" and "equality, equal opportunities" were present with a weight of $3.5 \%, 0.9 \%$ and $0.9 \%$ respectively.

The primary functions of libraries are different from museums, but the least prioritized topics (identity, equality and quality leisure time) were the same. Identity was mentioned more often by library professionals than museum experts $(0.9 \%$ and $3.0 \%$ respectively), so it is possible, if respondents' responses reflect a wider societal reality, that libraries have a more important role in cultivating identity within a community than museums do (see Figure 4).

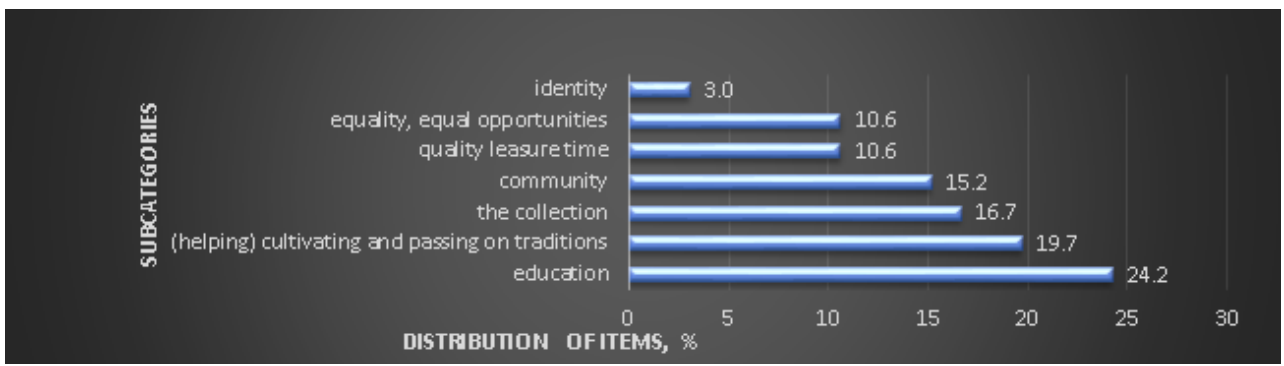

Figure 4: Relative importance of strengths and values as defined by library professionals 
According to experts that work there, libraries' main value does not lie in their collectionsanother significant difference compared to museums. The leading function here was seen as education $(24.2 \%)$ rather than the physical documents the institution keeps in its inventory $(16.7 \%)$. Libraries' second most important role was felt to be helping to cultivate and pass on traditions (19.7\%), closely followed by the collection itself and the institution's communitybuilding functions $(15.2 \%)$.

As might be anticipated for an active institution (see the corresponding section in the theoretical framework), experts in community education place community-building as their institution's main strength; 69.1\% of values and strengths mentioned by this cohort corresponded to the "community" subcategory (see Figure 5). Their second most important role was felt to be helping to cultivate and pass on traditions (17.6\%), with respondents placing emphasis on local traditions. "Quality leisure time" was rated more highly in the estimation of community centre workers $(5.9 \%)$ than museum professionals $(3.5 \%)$, but not as highly as by library staff $(10.6 \%)$. Among the three type of cultural institutions, educational functions and the collection received the lowest share here, which can be explained by the fact that community centres do not usually possess a significant number of items to exhibit or loan. To summarise, the main task community education experts feel their institutions fulfil lies in building and nurturing local communities, to keep the member of these communities together.

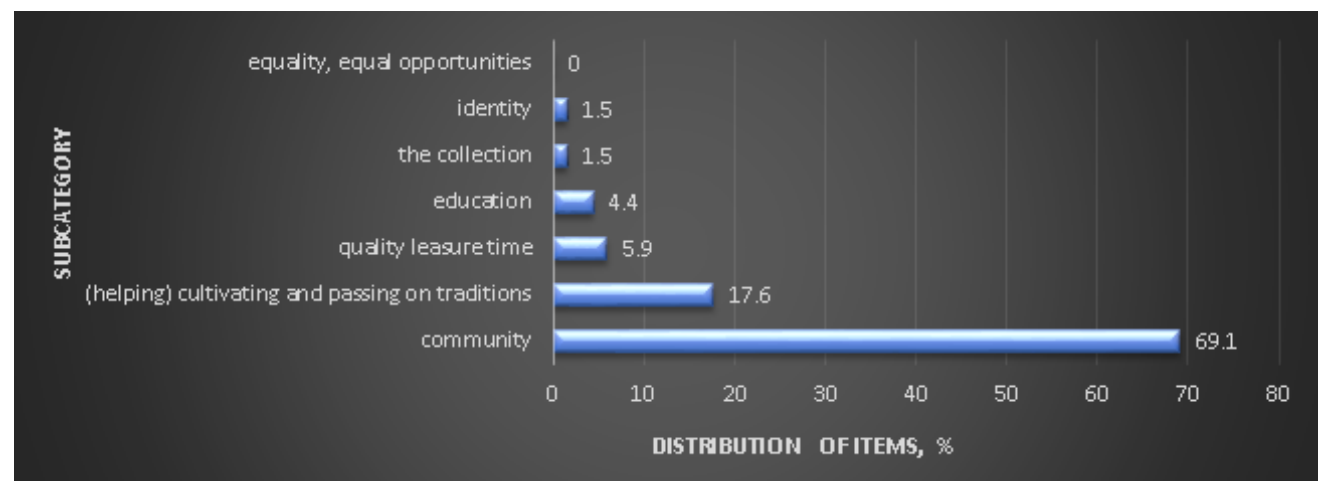

Figure 5: Relative importance of strengths and values as defined by community centre professionals

\section{Problems, areas to develop}

This main category contains a vast amount of information and it is the largest category of the analysis, with 475 references coded. In spite of being linked to two questions, this category is homogenous since both questions refer to currently existing problems relating to lack or scarcity of resources, and respondents were very focused on these issues in their answers.

\section{The most urgent problems}

Patterns emerging during the analysis of problems and areas to develop can be seen in Figure 6: 


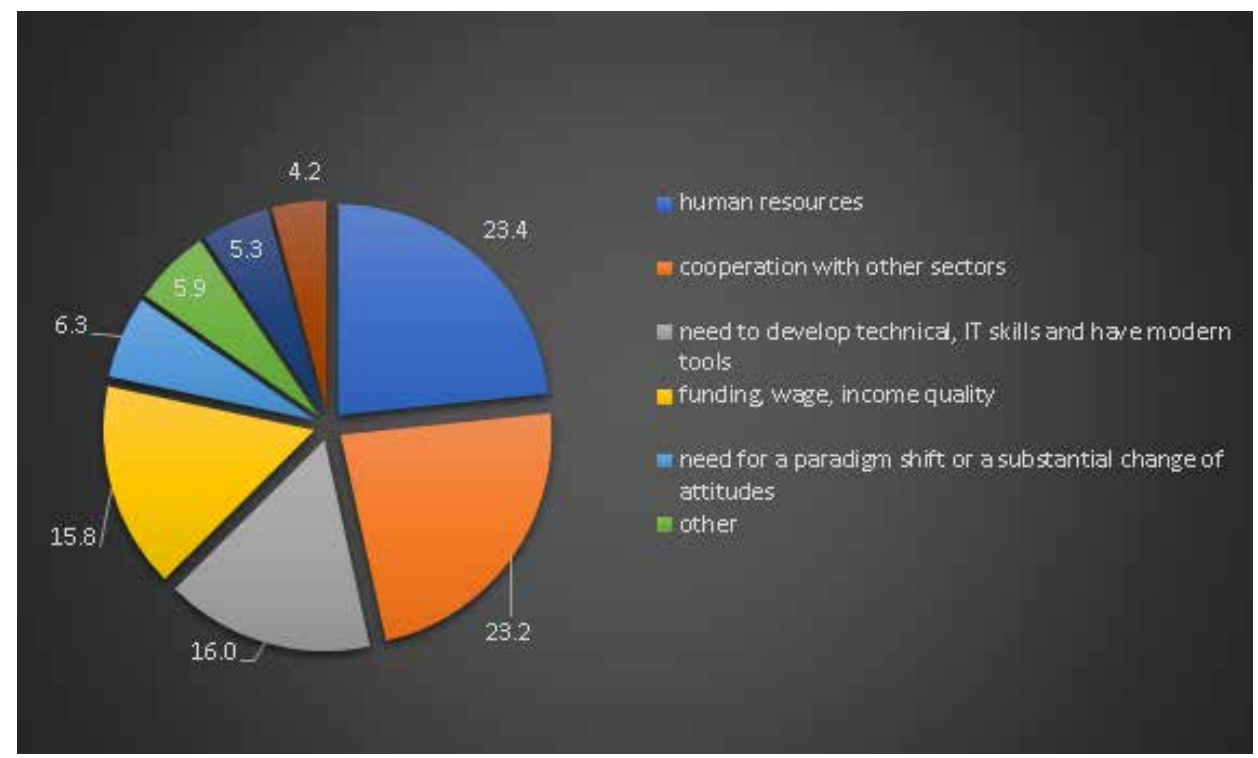

Figure 6: Problems, areas to develop (distribution, in percent)

The two main areas of concern to emerge were around human resources $(23.4 \%)$ and cooperation with other sectors $(23.2 \%)$. According to the respondents, not just institutions, but the profession as a whole is suffering from a lack of suitably trained staff. Furthermore, it is not only the present workforce that is affected: it is starting to become an issue of potential workforce supply as well. Ever fewer people are choosing cultural fields of work, in decisions which are often made before applying for university courses. People who do choose this field of work often drop out to pursue something else, which, combined with a lack of technical staff, poses an even bigger challenge. The core of the problem can be found in the lack of funding: people who work in this field are underpaid and there are barely any grants for specific programs, projects and events, which means it would basically be impossible to employ the requisite number of people, even if a lack of suitably trained professionals was not a problem. There is a general uncertainty in the sector which comes across strongly in the following quotes:

“Those working in the field of public collections haven't had a salary raise since 2008 , extra pay was introduced in 2017, but that only lasts until November. Due to the outdated salary table, additional money must be assigned to complete the salaries in order to meet the national minimum wage, which is a humiliating situation. Due to the increase of minimum wage in January, the recently graduated workforce's salary won't even reach minimum wage. This is a serious issue that prevents professional innovation and development. The situation in university libraries and private institutions is also very similar."

"We need a solution to adjust employee salaries as soon as possible because experienced professionals are leaving these institutions." 
Another issue was the state of technical equipment and the skills needed to use them properly $(16 \%)$. This subcategory included all mentions referring to the technical environment- that is, to the presence and accessibility of necessary hardware and software, including its installation in the institution's brick-and-mortar establishment; for example automatic doors, sensors, wallmounted interactive multitouch display cases, and so on. According to the aggregated answers, even basic technical resources are scarce, with some institutions using decades-old technology. Technicians cannot carry out their work professionally with these outdated tools, which puts cultural institutions at a disadvantage when competing for visitors. Cultural institutions need modern equipment and an adequate workforce; however, this cannot be achieved under current funding models.

Another important area respondents mentioned, giving it similar weight to technical underresourcing, was issues related to funding, wages and income quality (15.8\%).

It is important to note that $42 \%$ of the problems raised by respondents were directly related to a lack of resources. Looking at spontaneous mentions, the figure was even higher, at 54\%. This means half of the problems mentioned by professionals working in these institutions are directly related to lack of financing and resources. All in all, it is easy to deduct that problems such as a lack of trained staff, poor salaries, out-of-date tools and general underfunding all feed back into a vicious circle of diminishing funds as visitor numbers dwindle. If better funding for the future is not secured, the relevance of these institutions and the number of visitors will continue to decrease, and the mediation of culture will eventually fall into private hands. If that happens, culture will no longer be a basic right for all citizens, but something that only the more privileged can afford.

\section{Other important issues}

Although the majority of problems raised by respondents were directly related to lack of resources, there were other issues as well, albeit of lesser importance:

- importance of change of perception and of a paradigm shift in thinking, intellectual modernization

- equal opportunities in society

- lack of marketing

As the replies show, the Hungarian cultural sphere requires a comprehensive change in order to guarantee its success. Changes need to be implemented regarding financial aid and equipment, and the workforce itself needs training to adapt to modern practices. Without these inputs, the existence of cultural institutions is at risk.

\section{Problematic areas by sub-sector}

A more nuanced view of problematic areas can be gained by examining the relative weight given to each by professionals from museums, libraries and community centres (Figures 7, 8 and 9 respectively). 


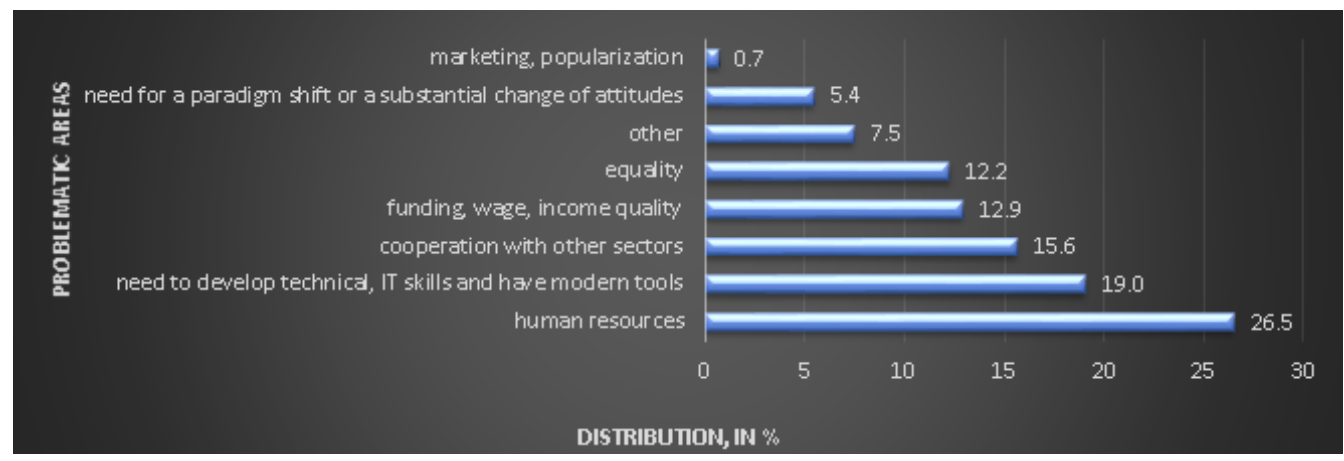

Figure 7: Areas to address, according to museum professionals

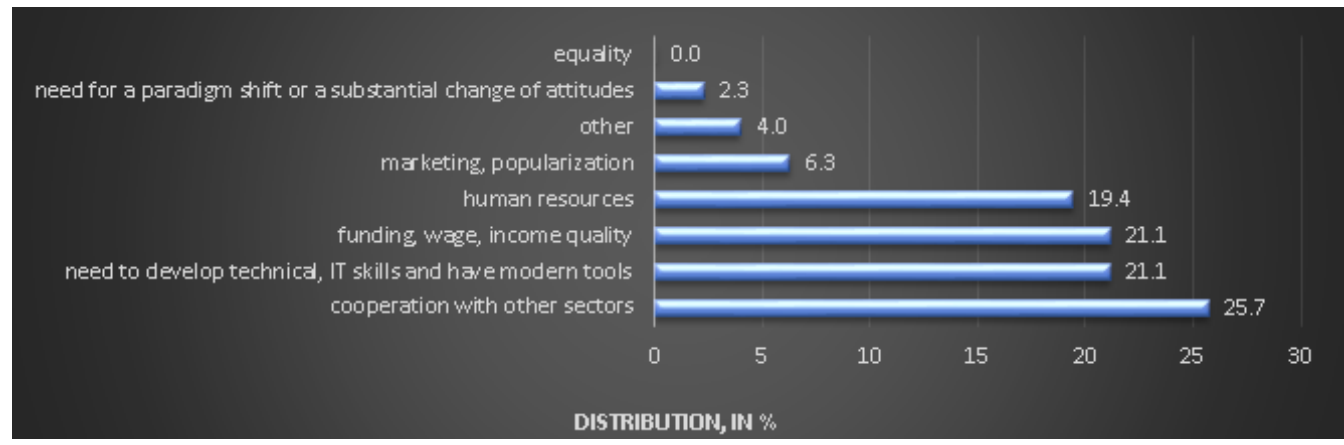

Figure 8: Areas to address, according to library professionals

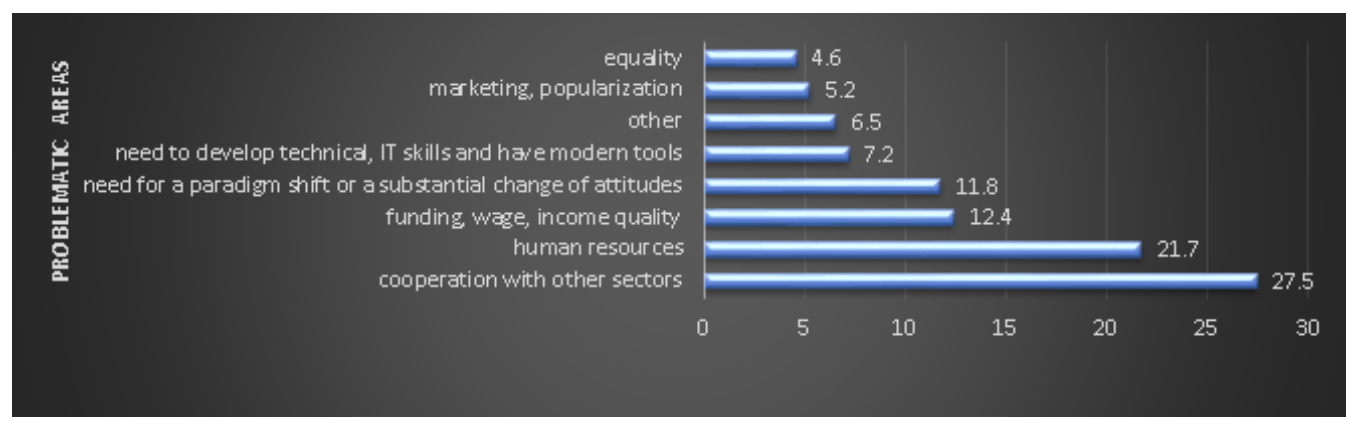

Figure 9: Areas to address, according to community centres

The graphs illustrate that the directors of community centres treat obsolescence of equipment as a secondary problem, which is not surprising considering their main task is not presenting books, documents or collections. The digitization of books and the proper storage of priceless artefacts is a more pressing issue for libraries and museums, hence concerns about out-of-date equipment are more common among museum (19.4\%) and library staff (21.7\%). However, the real issue, particularly for museums and community centres, is the lack of trained professionals in the cultural sector. Finding suitable employees becomes even harder given the need for workers with multidisciplinary skills to fit the complex nature of work within cultural institutions. There is a huge shortage of trained workers, which suggests that these jobs need to be made more appealing in order to attract people to the sector. Financing and salary were among the top four factors mentioned in all institutions. 
All in all, directors of all institutional types mentioned a lack of technical resources, a poorly trained workforce and poor finance and salaries, suggesting that these were the three main issues faced in Hungary's cultural institutions in 2017. The last of these - finance and funding - exacerbate the other two problems.

These practical, resource-based problems in museums, libraries and community centres are the most pressing ones, since modernisation and adaptation to the expectations of contemporary audiences cannot happen without suitable investment in human and technological resources. Informants noted that in institutions which are popular and see a high footfall of visitors, you will find underpaid but enthusiastic staff. These places are popular because of the hard work of these unsung, everyday heroes and not because of the system.

"[C]ertain institutions may be popular compared to others; however, this is because of the individual performance of the directors, employees and their community, not because of the way the system works."

Survey responses also contained politically loaded observations and opinions, some reflecting governmental policy, some responding to (the perceived lack of) governmental competence when dealing with cultural issues:

'We don't agree with the integrated institution model introduced in 2017 by the government. This was made up by someone sitting in front of a desk in Budapest, without any experience whatsoever. This could seriously DAMAGE the way these institutions work."

The survey generated many similar responses reflecting recent governmental policy changes, regardless of the question being asked.

According to the responses, cooperation in the cultural sphere can be achieved by:

- designing strategies together;

- designing websites and other online interfaces showing the activities and programmes occurring in certain city;

- ensuring that cultural institutions within a city are not in competition with each other by planning programs together and cooperating throughout the year;

- $\quad$ submitting tenders that encourage cooperation;

- using the same advertising spaces, cross-promotion, joint planning of advertising strategies and marketing;

- creating programs, projects, events and workshops together;

- creating a single portal to access multiple institutions' catalogues (e.g. a combined database for all the libraries within a certain area);

- initiating courses and advanced training across institutions, allowing employees to gain insight into their colleagues' work.

These opportunities for cooperation were mentioned several times in survey responses, representing the backbone of the main suggestions for cooperation. 


\section{Visions - The ideal situation in ten years' time}

Analysis of survey responses revealed two main pathways towards the future highlighted by cultural institution professionals. One related to questions concerning the function of cultural institutions; the other related to operational costs and related factors. These main paths are analysed below as two subcategories of "Vision", further subdivided into topics (T):

\section{SUBCATEGORY 1: Function}

Concerning the functions of cultural institutions, visions tended to draw into three topics:

- T1: the institution as a space suitable for sharing time together, as a community centre and a multifunctional public space.

- T2: the institution as a thinktank or a workshop for ideas.

- T3: the institution as a target for tourism.

SUBCATEGORY 2: operational factors, costs

Concerning operational factors and costs, three main topics identified were:

- T1: financial stability

- T2: human resources

- T3: modernization (including digital presence, need for modern infrastructure, equipment etc.)

Regarding a common vision for the future functions of cultural institutions, answers revolved around three possible roles (from a total of 177 references coded):

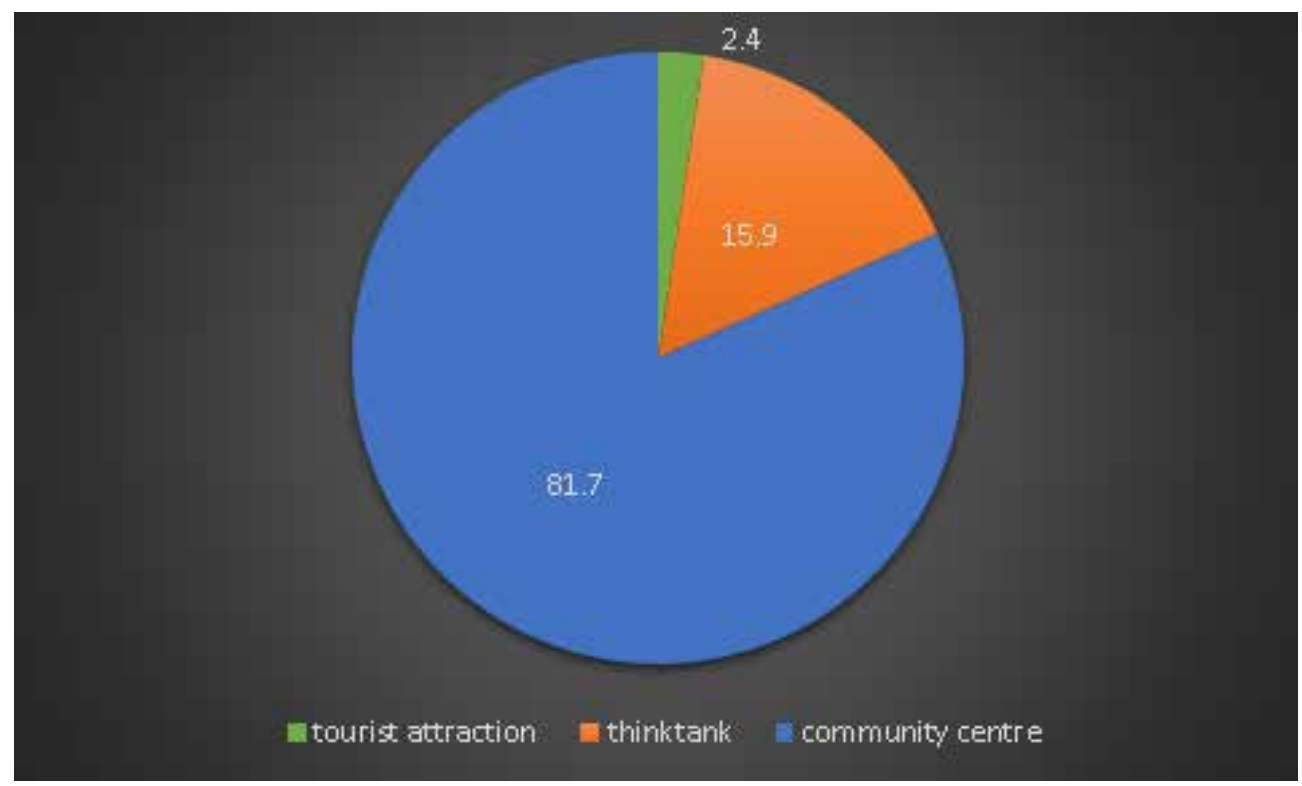

Figure 10: Visions: what should cultural institutions be in ten years' time?

Cultural institutions of the future are mostly imagined as a kind of community centre, offering various services for their specific communities. Even when examining responses from library, museum and community centre professionals separately, responses show the same 
order of priorities, with minimal difference in weight.

However, the idea that the respondent's institution should be a tourist attraction in the future only appeared among museum experts. Based on the number of coded mentions, experts in museums (8) and libraries (4) were considerably more eager to see their institutions acting as thinktanks in the future than their counterparts in community centres. The "community centre" function was, unsurprisingly, the most important vision for the future of community centres, mentioned 37 times by professionals who worked in one, compared to 21 mentions by museum professionals and nine by library professionals.

In the second subcategory, results from across the sector showed that T3 - digital presence, modern infrastructure and equipment, and other thoughts on modernization-received $67.4 \%$ of all mentions connected to operational costs (from a total of 95 references coded). More specifically, when asked about the ideal situation for their institution in ten years' time, respondents imagined operating in more modern and better equipped buildings compared to now. Although stable financing was only specified in $4.2 \%$ of responses, the other two major visions for the future-technical modernisation and improved staffing - are absolutely reliant on increased funding, so T1 is a more important factor than the actual number of coded mentions suggests.'

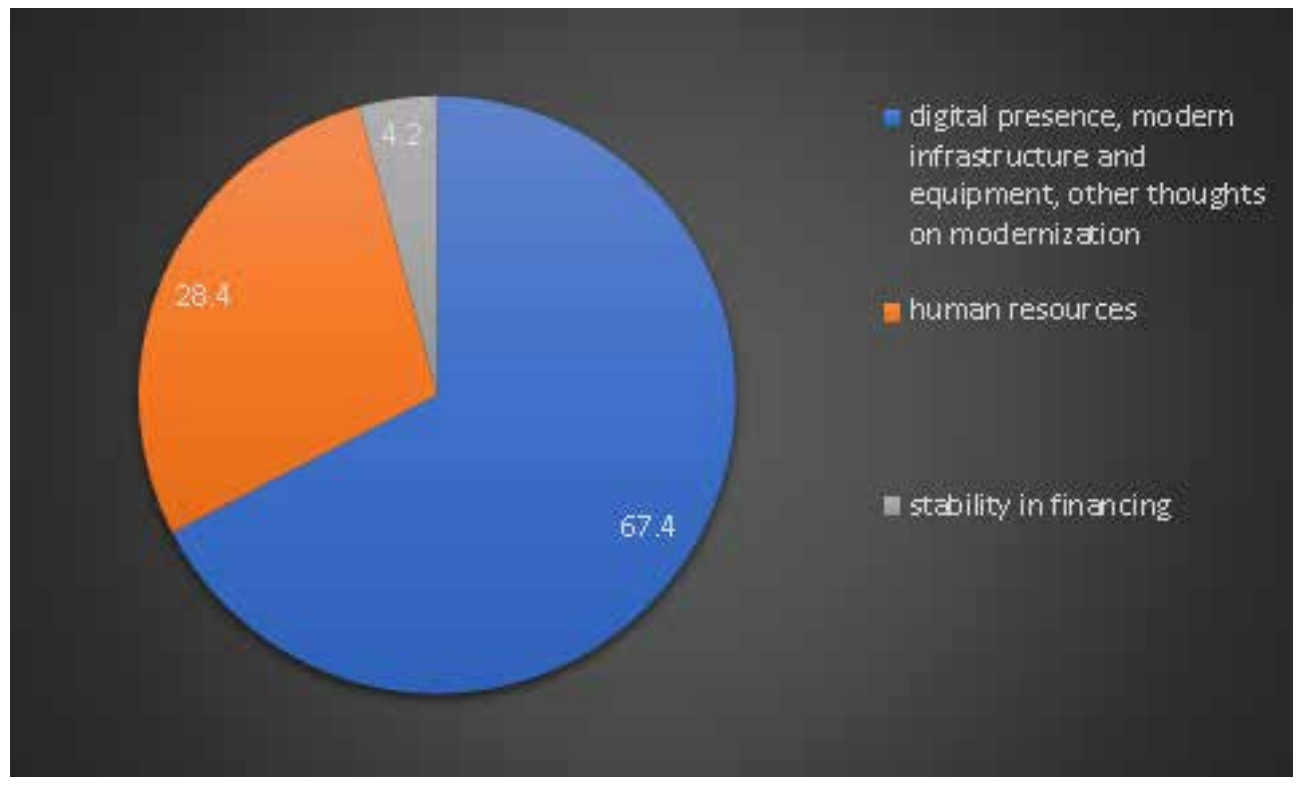

Figure 11: Visions: Operational factors, costs

To conclude, it can be said that respondents working in cultural institutions wished for more funding, primarily to upgrade technical equipment and infrastructure, but also to tackle shortfalls in human resources. Respondents expressed a desire for institutions

"where visitors are greeted by nice, professional people; which are adequately equipped and furnished, according to the standards of the age; where members of the local community, wider or smaller, can enjoy quality time." 
János Tóth: Values, strengths and futures of museums, libraries and community centres as seen by experts...

Exasperation over the current situation showed itself on several occasions when respondents were asked about their vision for the future, with one expert replying, "Being in the situation we are in, I cannot form such vision".

However, in spite of the general apathy expressed in quite a large number of answers, there was another, more positive vision that emerged from the professionals' responses. This vison was of public space for everyone; a modern, multifunctional intellectual workshop, suitable for all ages; a future cultural institution where people want to spend their free time; an institution capable of building and nurturing communities:

"It should become a veritable agora, a market for urban intellectuals, a meeting point."

"The elderly should be made aware that libraries are not only for books you can read in your free time. They can learn here how to communicate online with their grandchild, how to use social media, how to gather recipes for Sunday dinner, how to discern between fake news and legit news."

One respondent described their vision of their institution's future as a place that is "Bright, spacious, comfortable, transparent, and loved." Another felt their institution

"should remain similar to the current one, be an open, extroverted organization, able to react to changes, to initiate changes, not living on routine work, an organization where spaces keep their modern feeling, and their infrastructure makes it possible to provide twenty-first-century services and support, [rather than] emanate a pitiable retro feeling."

\section{Summary}

In this study we have presented what Hungarian community centre, library and museum professionals think about the values and strengths of their institutions, what problems they are aware of and focus on, and how they envisage their institution's future role in society. The results presented here are not to be considered as final, but will be used to construct the second-round questionnaire in which these answers, together with the answers to other firstround questions not analysed in this study, will be summarised and formulated into a series of more specific questions.

The main contribution of the current study was to identify consensus and dissensus in what experts think about the values, strengths and problems of their respective institutions, and how they see the future of their institution ten years from now. One major area of consensus related to finances and funding, with professionals across the board identifying this as the ultimate barrier to the proper functioning of their institution. In particular, respondents expressed an urgent need for reform with regards to human resources, staff training, and the modernisation of infrastructure, to avoid a serious decline in visitor numbers. Visions for the future of cultural institutions centred around their role as spaces that bring people together to share ideas and build shared communities. 
Until cultural institutions receive the support they need to bring about these developments, positive results remain tied to the commitment of individual staff members, often underpaid, who sacrifice their own time and energy, fuelled only by their enthusiasm and sense of duty. As one respondent said:

"The answer is simple. Put your heart into it (even when you're significantly underpaid)!"

\section{References}

ADLER, M. and ZIGLIO, E. (1996) (ed.). Gazing into the oracle: The Delphi method and its application to social policy and public health. London: Jessica Kingsley Publishers.

ANDERSON, B. R. (1991). Imagined communities: reflections on the origin and spread of nationalism (Revised and extended. ed.). London: Verso.

APPADURAI, A. and BRECKENRIDGE, C. A. (1992). Museums are good to think: Heritage on view in India. In: I. Karp, C. M. Kreamer, S. Lavine (eds.). Museums and communities: The politics of public culture. Washington: Smithsonian Institution Press.

ARAPOVICS, M.; PONYI, L. and BODOG, A. (2019) (eds.). The Examination of Cultural Community Development Processes in the Municipalities of Hungary. Budapest: Hungarian Open Air Museum-Museum Education and Methodology Centre, NMI Institute for Culture Non-profit Ltd and National Széchényi Library.

ASSMANN, J. (2011). Cultural Memory and Early Civilization: Writing, Remembrance, and Political Imagination. Cambridge: Cambridge University Press.

BAUMFIELD, V. M., CONROY, J. C., DAVIS, R. A. and LUNDIE, D. C. (2012). The Delphi method: gathering expert opinion in religious education. British Journal of Religious Education, vol. 34, No 1, pp. 5-19.

BEAZLEY, I.; BOWEN, J. P.; MCDAID, S. and LIU, A. H.-Y. (2010). Dulwich OnView: An art museum-based virtual community generated by the local community. In: A. Seal, J. P. Bowen, \& $\mathrm{K} . \mathrm{Ng}$ (eds.). EVA London 2010 Conference Proceedings, Electronic Workshops in Computing (eWiC), British Computer Society, pp. 79-86. Available at http://ewic.bcs.org/content/ ConWebDoc/36053 [Accessed 12/12/2017]

BLACK, G. (2011). Transforming museums in the 21st century. London: Routledge.

CARTER, J. and ORANGE, J. (2012). Contentious Terrain: Defining a human rights museology. Museum of Management and Curatorship 27, pp. 2111-2127.

DAVENPORT, D. H. and HARRIS, J. G. (2007). Competing on Analytics: The New Science of Winning. Boston: HBS Press.

DEMPSEY, L. (2000). Scientific, Industrial, and Cultural Heritage: a shared approach. A research framework for digital libraries, museums and archives. In: Ariadne, Issue 22, 2000 http://www.ariadne.ac.uk/issue/22/dempsey/

FULLER, T. and LOOGMA, K. (2009). Constructing futures: a social constructionist perspective on foresight methodology. Futures, 41, pp. 71-79. 
János Tóth: Values, strengths and futures of museums, libraries and community centres as seen by experts...

GIANNINI, T. and BOWEN, J. P. (2015). A New York Museums and Pratt partnership: Building Web collections and preparing museum professionals for the digital world. In: MW2015: Museums and the Web 2015, Chicago, USA, 8-11 April. http://mw2015.museumsandtheweb. $\mathrm{com} /$ paper/a-new-yorkmuseums-and-pratt-partnership-building-web-collectionsandpreparing-museum-professionals-for-the-digital-world [Accessed 12/12/2017]

HALL, S. (1997). Representation: Cultural representations and signifying practices. Culture, Media \& Identities Series. Milton Keynes/London: The Open University \& Sage Publications Ltd.

HARRISON, R. (2013). Heritage: Critical Approaches. London: Routledge.

HUVILA, I. (2016). Change and stability in archives, libraries and museums: mapping professional experiences in Sweden. Information Research, vol. 21, No. 1, paper memo 5. http://InformationR.net/ir/21-1/memo/memo5.html [Accessed 12/12/2017]

HUVILA, I. (2014). Archives, Libraries and Museums in the Contemporary Society: Perspectives of the Professionals. In: Conference 2014 Proceedings pp. 45-64. doi:10.9776/14032

GIBSON, H., Morris, A. and Cleeve, M. (2007). Links Between Libraries and Museums: Investigating Museum-Library Collaboration in England and the USA. Libri, vol. 57, no. 2, pp. 53-64.

GRAHAM, B., ASHWORTH, G. J., \& TUNBRIDGE, J.E. (2004). A geography of heritage: power, culture and economy. London: Arnold.

MACEVICIUTE, E. \& WILSON, T. D. (2009). A Delphi investigation into the research needs in Swedish librarianship. Information Research, vol. 14, No. 4, paper 419. http:/ InformationR. net/ir/14-4/paper419.html [Accessed 12/12/2017]

MCBRIDE, M. F., et al. (2012). Structured elicitation of expert judgments for threatened species assessment: a case study on a continental scale using email. In: Methods in Ecology and Evolution vol. 3, No. 5, pp. 906-920.

O'FAIRCHEALLAIGH, C. (2010). Public participation and environmental impact assessment: purposes, implications, and lessons for public policymaking. Environmental Impact Assessment Review, vol. 30, No. 1, pp. 19-27.

ORANGE, J. A. (2016). Translating Law into Practice: Museums and a Human Rights Community of Practice. Human Rights Quarterly 38, No. 3, pp. 706-735 doi: 10.1353/ hrq.2016.0049

PARRY, R. (2010). Museums in a Digital Age. London: Routledge.

SAUTER, V. L. (2010). Decision Support Systems for Business Intelligence. New Jersey: John Wiley \& Sons.

SCHEELE, D. S. (1975). Reality construction as a product of Delphi interaction. In: The Delphi method: Techniques and applications, ed. Harold A. Linstone and Mur-ray Turoff. Reading, MA: Addison-Wesley.

STOCCHETTI, M. (2017). Digital Visuality and Social Representation. Research Notes on the Visual Construction of Meaning. KOME-An International Journal of Pure Communication Inquiry, vol. 5, No. 2, pp. 38-56.

Supporting Cultural Heritage https://ec.europa.eu/culture/policy/culture-policies/culturalheritage_en (Accessed 12/12/2017)

TONTA, Y. (2008). Libraries and Museums in the Flat World: Are they Becoming Virtual Destinations? Library Collections, Acquisitions, and Technical Services 32, No. 1, pp. 1-9. doi: 10.1016/j.lcats.2008.05.002 
YARROW, A., CLUBB, B. and Draper, J-L. (2008). Public Libraries, Archives and Museums: Trends in Collaboration and Co-operation. International Federation of Library Associations and Institutions Professional Reports 108. Available online: https://www.ifla.org/ publications/ifla-professional-reports-108 [Accessed 12/12/2017]

VEGLIS, A. and MANIOU, T. (2018) The Mediated Data Model of Communication Flow: Big Data and Data Journalism. In: KOME - An International Journal of Pure Communication Inquiry, vol. 6, No. 2, pp. 32-43. 